\title{
CORRESPONDENCE
}

\author{
THE EARTHED ANTEN NA
}

SIR,

I have read with much interest the articles by the distinguished contributors to the first number of your Fournal, but I am surprised to note that Sir Robert WatsonWatt suggests that 'Professor Popoff was probably the first to use the earthed antenna which brought radio-telegraphy out of the laboratory and into life.'

It has always been understood in the Marconi organization that Marconi's great practical contribution to the advancement of the art of wireless communication lay in his introduction of the earthed aerial in 1896 , thereby bringing the mathematical investigations of Maxwell and the laboratory work of Hertz to the service of mankind.

The following references made by contemporary observers may serve to correct any mistaken impression.

J. J. Fahie, in A History of Wireless Telegraphy, 1 p. 200, records 'Between 1895 and I 896 Messrs. Popoff, Minchin, Rutherford and others applied the Hertzian method to the study of atmospheric electricity; and their mode of procedure, in the use of detectors in connection with vertical exploring rods, was much the same as that of Marconi.'

Popoff's arrangement was very similar to that of Marconi, and Fahie goes on to say that 'Prof. Popoff's plans were communicated to the Physico-Chemical Society of St. Petersburg in April 1895'; and in a further note, dated December 1895, he adds ' $I$ entertain the hope that when my apparatus is perfected it will be applicable to the transmission of signals to a distance by means of rapid electric vibrationswhen, in fact, a sufficiently powerful generator of these vibrations is discovered.' And adds as a footnote: 'On hearing of Marconi's success in England, Prof. Popoff tried his apparatus quasi telegraph (presumably using more sensitive detectors), and in April 1897 succeeded in signalling through a space of 1 kilometre, then through $1 \frac{1}{2}$, and finally through 5 kilometres, with vertical wires, 18 metres high.'

A similar account of these early experiments is given by Prof. Fleming in his Principles of Electric Wave Telegraphy and Telephony, ${ }^{2}$ and he goes on to point out that at this date (January 1896 ) no one had actually given any exhibition in public of the transmission of intelligence by alphabetic or telegraphic signals by 'wireless.'

Marconi's first patent for his system of Wireless Telegraphy is dated 2 June 1896 , and describes the earthed aerial, together with a number of improvements both in the design of the coherer itself, and the associated circuits. It was this combination which made possible wireless telegraphy.

It is also interesting to note that Prof. Slaby, ${ }^{3}$ writing in The Century Magazine, April 1898, said: '. . . In the English professional journals an attempt has been made to deny novelty to the method of Marconi. . . . Then he has shown that such telegraphy (writing from afar) was to be made possible only through, on the one hand, earth connection between the apparatus, and, on the other, the use of long extended upright wires. By this simple but extraordinarily effective method he raised the power of radiation in the electric forces a hundredfold.'

I think this is sufficient evidence that the Marconi aerial was truly discovered and first used by Marconi.

Incidentally, on 28 April 1899 , the S.S. $R$. $F$. Matthews ran into the East Goodwin lightship during foggy weather and damaged the latter very severely. Fortunately, the lightship was fitted with Marconi's new system of wireless telegraphy and was able to summon assistance at once via the South Foreland lighthouse. It is believed that if this assistance had not been immediately forthcoming the light vessel would have foundered with the loss of all hands. 
I hope that this latter evidence will make clear that the first known case of wireless telegraphy being used for increasing the safety of life at sea was by means of Marconi equipment, using the Marconi system of wireless telegraphy.

I have the honour to remain,

Yours faithfully,

H. C. Van de Velde, Deputy Managing Director.

The Marconi International Marine Communication Co., Ltd., Marconi House, Chelmsford, Essex.

1 Fahie, J. J., 1899. A History of Wireless Telegraphy, $1838-1899$.

2 Fleming, J. A., 1906. Principles of Electric Wave Telegraphy \& Telephony.

s Slaby (Charlottenburg), April I898. 'The New Telegraphy', Century Magazine.

\section{AIDS TO LAND NAVIGATION}

SIR,

The importance attached to marine and air navigational aids tends to make the land aspect of the problem be forgotten. This aspect exists, and now, when opinions are formed, the views of members of the Institute on this subject could be of great value and would be most welcome.

Land navigation is normally carried out by map and compass and, where greater accuracy is required, by survey methods. In places, however, compasses become unreliable and maps inadequate; then an additional aid, either radio or DR is desirable.

In general a ground-to-ground radio system necessitates a comparatively low frequency. With a vehicle-borne receiver the aim would be to provide over a wide coverage (in the order of 200 miles) co-ordinate presentation down to 100 yards. with an accuracy of 200 yards. For mapping purposes, that is, the filling in of subsidiary detail, this degree of accuracy is insufficient. It might however be possible by limiting the coverage to 20 miles, and employing mobile transmitters, and perhaps using the same receiver circuits, to read down to ro yards with an accuracy of 20 yards. With mobile transmitters there are difficulties in producing the necessary overlay to the area being mapped.

An aid working entirely by radio means is not necessarily the solution. The radio spectrum is crowded, and a DR system independent of radio is therefore attractive. Such a system would have one great advantage, in that when an accurate fix is obtained by other means, all previous running errors would be eliminated; also the serious disadvantage of the inaccuracy inherent in the magnetic compass when mounted in a vehicle, and also when used in high latitudes. A DR system using a radio compass is a possible solution.

It would be of interest to hear the views of members on these possibilities.

Yours faithfully,

G. Chaldecott.

\section{Bekyntons Cottage, \\ East Chisenbury, Nr. Marlborough, \\ Wilts.}

